\title{
Extracorporeal carbon dioxide removal for acute hypercapnic exacerbations of chronic obstructive pulmonary disease: study protocol for a randomised controlled trial
}

\author{
Nicholas A. Barrett ${ }^{1,2^{*}}$, Eirini Kostakou ${ }^{1}$, Nicholas Hart ${ }^{2,3}$, Abdel Douiri ${ }^{4,5}$ and Luigi Camporota ${ }^{1,2}$
}

\begin{abstract}
Background: Chronic obstructive pulmonary disease (COPD) is a common cause of chronic respiratory failure and its course is punctuated by a series of acute exacerbations which commonly lead to hospital admission. Exacerbations are managed through the application of non-invasive ventilation and, when this fails, tracheal intubation and mechanical ventilation. The need for mechanical ventilation significantly increases the risk of death. An alternative therapy, extracorporeal carbon dioxide removal $\left(\mathrm{ECCO}_{2} \mathrm{R}\right)$, has been shown to be efficacious in removing carbon dioxide from the blood; however, its impact on respiratory physiology and patient outcomes has not been explored.
\end{abstract}

Methods/design: A randomised controlled open label trial of patients (12 in each arm) with acute exacerbations of COPD at risk of failing conventional therapy (NIV) randomised to either remaining on NIV or having $\mathrm{ECCO}_{2} \mathrm{R}$ added to NIV with a primary endpoint of time to cessation of NIV. The change in respiratory physiology following the application of $\mathrm{ECCO}_{2} \mathrm{R}$ and/or NIV will be measured using electrical impedance tomography, oesophageal pressure and parasternal electromyography. Additional outcomes, including patient tolerance, outcomes, need for readmission, changes in blood gases and biochemistry and procedural complications, will be measured. Physiological changes will be compared within one patient over time and between the two groups. Healthcare costs in the UK system will also be compared between the two groups.

Discussion: COPD is a common disease and exacerbations are a leading cause of hospital admission in the UK and worldwide, with a sizeable mortality. The management of patients with COPD consumes significant hospital and financial resources. This study seeks to understand the feasibility of a novel approach to the management of patients with acute exacerbations of COPD as well as to understand the underlying physiological changes to explain why the approach does or does not assist this patient cohort. Detailed respiratory physiology has not been previously undertaken using this technique and there are no other randomised controlled trials currently in the literature.

Trial registration: ClinicalTrials.gov, NCT02086084.

Keywords: Acute exacerbations of chronic obstructive pulmonary disease, COPD, Extracorporeal $\mathrm{CO}_{2}$ removal, ECCO2R, Non-invasive ventilation, NIV

\footnotetext{
* Correspondence: nicholas.barrett@gstt.nhs.uk

'Department of Critical Care, Guy's and St Thomas' NHS Foundation Trust, Westminster Bridge Rd, London SE1 7EH, UK

${ }^{2}$ Centre for Human \& Applied Physiological Sciences (CHAPS), School of Basic

\& Medical Biosciences, Faculty of Life Sciences \& Medicine, King's College

London, London, UK

Full list of author information is available at the end of the article
}

(c) The Author(s). 2019 Open Access This article is distributed under the terms of the Creative Commons Attribution 4.0 International License (http://creativecommons.org/licenses/by/4.0/), which permits unrestricted use, distribution, and reproduction in any medium, provided you give appropriate credit to the original author(s) and the source, provide a link to the Creative Commons license, and indicate if changes were made. The Creative Commons Public Domain Dedication waiver (http://creativecommons.org/publicdomain/zero/1.0/) applies to the data made available in this article, unless otherwise stated. 


\section{Background}

Chronic obstructive pulmonary disease (COPD) is a syndrome characterised by progressive and not fully reversible expiratory airway flow limitation. The underlying pathophysiology of COPD is the progressive destruction of the elastic and alveolar tissue within the lung, resulting in reduced expiratory flow rates, maldistributed ventilation, gas trapping and hyperinflation, which in turn lead to diaphragmatic flattening and inefficient respiration. COPD is punctuated by recurrent exacerbations characterised by a worsening of the patient's dyspnoea, cough and/or sputum production beyond day-to-day variations [1]. Acute exacerbations are an important cause of hospital admission and impact on patients' quality of life [2-5], as well as having a huge societal impact amounting to $\sim 6 \%$ of the total healthcare cost [6]. Exacerbations also accelerate disease progression, leading to a progressive stepwise functional decline [7-13].

Patients with significant exacerbations of COPD resulting in hypercapnic respiratory acidosis $\left(\mathrm{PaCO}_{2}>6 \mathrm{kPa}(45\right.$ $\mathrm{mmHg}$ ) and $\mathrm{pH}<7.35)$ have life-threatening respiratory failure and non-invasive ventilation (NIV) has significant mortality benefits for patients [1, 14-19]. NIV provides both inspiratory and expiratory pressure, which, by splinting open collapsing airways by matching intrinsic positive end expiratory pressure (PEEP) and providing positive pressure to assist tiring respiratory muscles, enhances ventilation. This enables an improved ventilation-perfusion relationship, improves gas exchange and simultaneously reduces oxygen consumption and carbon dioxide production because of the reduction in work of the respiratory muscles $[16,20]$. Although NIV has substantially improved mortality (risk ratio $0.54,95 \% \mathrm{CI} 0.38$ to 0.76 ) and decreased the need for intubation (risk ratio 0.36; 95\% CI 0.28 to 0.46 ) in patients with an acute exacerbation of COPD [16], 15-30\% of patients commencing NIV fail and require intubation and mechanical ventilation [21-23]. Risk factors for NIV failure include obtundation, hypercapnoea, persisting respiratory acidosis $(\mathrm{pH}<7.30)$, higher APACHE II score (>28), tachypnoea ( $>29)$ and lack of improvement in the first $1-2 \mathrm{~h}$ of therapy [23-27]. Patients who fail NIV and require intubation have a significantly higher mortality than those who improve with NIV (30\% vs < $10 \%)$ [28], with mortality rates up to $57 \%$ in some case series [29].

Extracorporeal $\mathrm{CO}_{2}$ removal $\left(\mathrm{ECCO}_{2} \mathrm{R}\right)$ is the use of an extracorporeal circuit with a gas-exchanging membrane to provide clearance of $\mathrm{CO}_{2}$ directly from the blood $[30,31] . \mathrm{ECCO}_{2} \mathrm{R}$ has been reported to clear $\mathrm{CO}_{2}$ in the pre-clinical setting [32-37] as well as in uncontrolled case series which have included patients with acute exacerbation of COPD (AECOPD) [35, 38-42]. Potential benefits, including avoidance of intubation and early extubation, have been suggested from this retrospective work; however, a retrospective propensity matched case-control study using $\mathrm{ECCO}_{2} \mathrm{R}$ in $\mathrm{COPD}$ reported no significant improvement in mortality [43].

In addition to an unclear mortality benefit, it is also uncertain what the impact of $\mathrm{ECCO}_{2} \mathrm{R}$ is on native lung physiology. There is a widely reported reduction in respiratory rate and minute ventilation with improvements in $\mathrm{pH}$ and partial pressure of arterial $\mathrm{CO}_{2}[33,39,41,42,44,45]$. A small pilot study reported on the changes associated with $\mathrm{ECCO}_{2} \mathrm{R}$ in patients with COPD weaning from a ventilator and found that intrinsic PEEP, inspiratory pulmonary resistance and work of breathing were all reduced [46]. The authors postulated that part of the reduction in arterial $\mathrm{CO}_{2}$ seen in these patients was due to both the direct effects of $\mathrm{CO}_{2}$ removal and the reduced respiratory muscle work.

Despite $\mathrm{ECCO}_{2} \mathrm{R}$ showing promise as a method to reduce respiratory work and avoid intubation in uncontrolled case series and a propensity analysis, there have been no randomised controlled trials of $\mathrm{ECCO}_{2} \mathrm{R}$ in AECOPD and limited data are available on the physiological impact of $\mathrm{ECCO}_{2} \mathrm{R}$ on respiratory function and work of breathing in AECOPD. Hence, the key clinical role and physiological effect of $\mathrm{ECCO}_{2} \mathrm{R}$ needs greater definition and this work is aimed to explore both the outcome for patients with AECOPD commenced on $\mathrm{ECCO}_{2} \mathrm{R}$ and to better understand the physiological effects of $\mathrm{ECCO}_{2} \mathrm{R}$ in COPD exacerbations.

\section{Trial hypothesis and objectives}

The main hypotheses for the trial are that $\mathrm{ECCO}_{2} \mathrm{R}$ will lead to a significant reduction in the need for NIV and that this is mediated through a reduction in work of breathing secondary to the reduced $\mathrm{CO}_{2}$ burden. To explore work of breathing, several methods of assessing work of breathing will be undertaken: oesopheageal pressure monitoring, electrical impedance tomography and parasternal electromyography. These methods have not been used in combination before in this population; however, the benefit of using multimodal monitoring in the setting of acute exacerbations of COPD is that it will allow correlation between the different measurements and it is possible that one or more methods may not be able to be used in an individual patient.

\section{Methods/design \\ Design}

The trial is a prospective, randomised, controlled, with 1:1 allocation ratio unblinded study of $\mathrm{ECCO}_{2} \mathrm{R}$ in adults with AECOPD at risk of failing NIV as demonstrated by a persisting $\mathrm{pH}<7.30$ due to hypercapnoea after initial medical therapy and at least $1 \mathrm{~h}$ of NIV. The study will randomise a total of 24 patients, 12 in each treatment 
arm. Allocation was generated by computer-generated random number and concealed via opaque sealed envelopes.

\section{Inclusion criteria}

- Known COPD with an acute exacerbation. An acute exacerbation is defined as per the GOLD criteria as an increase in dyspnoea, cough and/or sputum over the patient's normal symptoms. A severe exacerbation is defined as one requiring hospital admission. Patients are known to have COPD when they have a previous diagnosis made and recorded on their medical records, data in support of this will include chest imaging, pulmonary function tests and clinical history/examination.

- Patients with a persistent arterial $\mathrm{pH}<7.30$ due primarily to hypercapnic respiratory failure after standard medical therapy and at least $1 \mathrm{~h}$ of NIV.

- Age over 18

\section{Exclusion criteria}

- Haemodynamic instability after ensuring euvolaemia

- Multiple organ failure requiring other organ supportive therapy, including indication for intubation and mechanical ventilation; this includes requirement for chronic organ supportive therapy (e.g. chronic non-invasive ventilation, dialysis)

- Known allergy/intolerance of heparin including known heparin-induced thrombosis and thrombocytopaenia

- Acute uncontrolled haemorrhage

- Intracerebral haemorrhage

- Recent (<6 months) ischaemic cerebrovascular accident

- Organ transplant recipient

- Expected to die within $24 \mathrm{~h}$ or with limitations of therapy in place precluding admission to critical care

- Venous abnormality or body habitus precluding cannulation

- Contraindication to NIV (as per British Thoracic Society recommendations):

- Facial burns/trauma/recent facial or upper airway surgery

- Vomiting

- Fixed upper airway obstruction

- Undrained pneumothorax

- Recent upper gastrointestinal surgery

- Inability to protect the airway

- Life-threatening hypoxaemia $\left(\mathrm{PaO}_{2} / \mathrm{FiO}_{2}<20 \mathrm{kPa}\right)$

- Bowel obstruction

- Patient refusal
- Pregnancy

- Severe hepatic failure (ascites, hepatic encephalopathy or bilirubin $>100 \mu \mathrm{mol} / \mathrm{L})$

- Severe chronic cardiac failure (NYHA class III or IV)

- Bleeding diathesis (INR $>1.5$, platelets $<80,000$ ) in the absence of anticoagulation therapy

\section{Primary outcome}

The primary outcome is the time taken to discontinuation of NIV in patients with acute, severe exacerbations of COPD through the addition of $\mathrm{ECCO}_{2} \mathrm{R}$ to standard care. The definition of discontinuation of NIV is cessation of NIV for at least $6 \mathrm{~h}$. Time to discontinuation will be measured from randomisation. The reason for discontinuation will be collected and successful discontinuation consists of being free of mechanical ventilation.

\section{Secondary outcome}

Secondary outcomes include the impact of ECCO2R on:

- Safety, including:

- Incidence of haemorrhagic complications-significant haemorrhage is defined as bleeding requiring transfusion of more than one unit of blood, intracerebral bleeding, bleeding requiring procedural intervention

- Incidence of thrombosis-all patients will have screening duplex ultrasound of the cannulated vessel

- Incidence of haemolysis defined by rising lactate dehydrogenase, bilirubin red cell fragments on a blood film and/or a rising plasma freehaemoglobin $(>0.5 \mathrm{~g} / \mathrm{dL})$

- Complications relating to cannulation including those at insertion-bleeding, vascular damage, pneumothorax and line infection, both clinically apparent (erythema/cellulitis at insertion site) and microbiologically proven (positive blood culture with concomitant line tip culture or line insertion site culture)

- Physiology, including respiratory rate, heart rate, blood pressure, temperature, arterial blood gases measured at time (T)0 min, T30 minutes, T $60 \mathrm{~min}$, then every fourth hour for the first $24 \mathrm{~h}$ and then every sixth hour until discontinuation of the acute phase of the trial

- Daily spirometry including forced vital capacity, forced expiratory volume in $1 \mathrm{~s}$ and the ratio between them

- Work of breathing, including electrical impedance tomography, parasternal electromyography and oesophageal pressure (these are described in detail below)

- Patient outcomes: 
- Mortality (ICU, hospital and 3 month)

- Length of stay (ICU, hospital)

- Need for intubation and where this occurs, duration of mechanical ventilation and need for tracheostomy, NIV failure and need for intubation will be decided by the clinical team managing the patient. Reason for NIV failure will be recorded by the research team.

- 3-Month hospital readmission rate

- Tolerance, assessed using both a numerical rating scale $(0-10)$ and visual acuity scale $(0-10 \mathrm{~cm})$ for both dyspnoea and comfort with the lowest reading being extremely uncomfortable and the highest being extremely comfortable.

Comparisons between the two different measures will be used without an absolute definition of comfort/discomfort.

- At 3-months following randomisation: COPD assessment test, St George's Respiratory Questionnaire, EuroQoL 5D. Comparisons between the different measures will be used without an absolute definition of success at follow-up.

- Cost-effectiveness with ICU bed day and consumables cost/quality adjusted life year (QALY)

\section{Trial procedures}

\section{Recruitment}

Potential study participants will be identified by the critical care outreach team, who are required to review every patient placed on NIV either on the wards or in the emergency department. The outreach team will inform the research team of potential study participants. The research team is available $24 \mathrm{~h}, 7$ days.

\section{Informed consent}

Informed consent/assent will be taken by appropriately trained investigators. Informed consent will be obtained prior to any study-related procedures being undertaken. The study participant or, if they lack capacity at the time of enrolment, the patient's consultee must personally sign and date the latest approved version of the informed consent form before any study-specific procedures are performed.

Written and verbal versions of the participant information and informed consent will be presented to the participants detailing no less than: the exact nature of the study; the implications and constraints of the protocol; the known side effects and any risks involved in taking part. It will be clearly stated that the participant is free to withdraw from the study at any time for any reason without prejudice to future care, and with no obligation to give the reason for withdrawal.

The participant or their consultee will be allowed up to $2 \mathrm{~h}$ to consider the information, and the opportunity to question the investigator or other independent parties to decide whether they will participate in the study. Written informed consent will then be obtained by means of participant or their consultee dated signature and dated signature of the person who presented and obtained the informed consent. The person who obtained the consent must be suitably qualified and experienced and have been authorised to do so by the Chief/ Principal Investigator. A copy of the signed informed consent will be given to the participants or their consultee. The original signed form will be retained at the study site. Once any participant has regained capacity they will be given written and verbal information about the study. Written informed consent will then be obtained by means of participant dated signature and dated signature of the person who presented and obtained the informed consent. It will be clearly stated that the participant is free to withdraw from the study at any time for any reason without prejudice to future care, and with no obligation to give the reason for withdrawal (Additional files 1).

\section{Randomisation and codebreaking}

Randomisation will be achieved using a computer-generated random list then stored as sequential sealed envelopes accessible to the primary study team. Other sites will randomise by telephone to the lead centre with envelopes opened and accessible only to the primary study team. The study participants, care providers and outcome assessors will be unblinded (open label).

\section{Data collection}

For eligible patients, clinical details will be collected after consent has been obtained and randomisation undertaken (Fig. 1). This will include details to confirm eligibility and basic demographic and medical details, including acute and chronic co-morbidity and medicines as well as a full physical examination. Details of baseline routine clinical investigations will be recorded. Participants will be allocated a sequential trial number to ensure participant anonymity and confidentiality. All data will be stored in de-identified password-protected databases held within the NHS. All paper documents will be transferred to the department of Critical Care at Guy's and St Thomas' NHS Foundation trust and stored in locked, fire-proof cabinets. All data transfers between institutions will conform to the information governance requirement of the NHS.

\section{Treatment of trial participants}

Following presentation, initial medical therapy and NIV will be commenced as per current local and UK national guidelines for the management of AECOPD 


\begin{tabular}{|c|c|c|c|c|}
\hline & \multicolumn{4}{|c|}{ STUDY PERIOD } \\
\hline & Enrolment & Allocation & Post-allocation & Close-out \\
\hline TIMEPOINT $^{\star *}$ & -1 hour & Time 0 & Daily whilst on NIV or ECCO2R & 3 months \\
\hline \multicolumn{5}{|l|}{ ENROLMENT: } \\
\hline \multirow{3}{*}{$\begin{array}{l}\text { Eligibility screen } \\
\text { Informed consent } \\
\text { Baseline physiology }\end{array}$} & $x$ & & & \\
\hline & & $\mathrm{x}$ & & \\
\hline & & $x$ & & \\
\hline Randomisation & & $x$ & & \\
\hline \multicolumn{5}{|l|}{ INTERVENTIONS: } \\
\hline \multirow{2}{*}{$\begin{array}{l}\text { [Intervention A] } \\
\text { [Intervention B] }\end{array}$} & & NIV & $\begin{array}{l}\text { Remain in arm until cessation of support } \\
\text { for } 6 \text { hours }\end{array}$ & \\
\hline & & $\mathrm{ECCO}_{2} \mathrm{R}$ & $\begin{array}{l}\text { Remain in arm until cessation of support } \\
\text { for } 6 \text { hours }\end{array}$ & \\
\hline \multicolumn{5}{|l|}{ ASSESSMENTS: } \\
\hline \multirow{2}{*}{ Physiological } & $\mathrm{x}$ & $\mathrm{x}$ & $x$ & \\
\hline & & & $x$ & \\
\hline \multirow[t]{2}{*}{$\begin{array}{r}\text { Oesophageal } \\
\text { pressure }\end{array}$} & & & $x$ & \\
\hline & & & $x$ & \\
\hline Parasternal EMG & & & $x$ & \\
\hline Spirometry & & & $x$ & \\
\hline Questionnaires & & & $x$ & \\
\hline $\begin{array}{r}\text { Follow-up } \\
\text { questionnaires }\end{array}$ & & & & $x$ \\
\hline
\end{tabular}

${ }^{*}$ Recommended content can be displayed using various schematic formats. See SPIRIT 2013

Explanation and Elaboration for examples from protocols.

** List specific timepoints in this row.

Fig. 1 Example template of recommended content for the schedule of enrolment, interventions, and assessments (recommended content can be displayed using various schematic formats; see SPIRIT 2013 Explanation and Elaboration for examples from protocols) (Additional File 2). ${ }^{* *}$ List specific timepoints in this row

[47]. All patients with AECOPD and $\mathrm{pH}<7.30$ after a minimum of $1 \mathrm{~h}$ NIV will be eligible for inclusion unless exclusion criteria are met. Once informed written consent is obtained from either the patient or their consultee if consent from the patient is not possible, patients will be randomised to the continuation of NIV alone or addition of $\mathrm{ECCO}_{2} \mathrm{R}$ to NIV. All other aspects of care, including acute, on-going and post-trial care, will be at the discretion of the clinical team. Monitoring will be the standard of care of ICU, including arterial and central venous access where this is deemed appropriate by the clinical team.

Patients who are randomised to continuation of NIV alone will be managed in accordance with hospital protocols and national guidelines for NIV. NIV will be titrated to achieve an arterial $\mathrm{pH}>7.35$, respiratory rate $<25$ and patient comfort with breathing.
Discontinuation of NIV will occur when judged appropriate by the patient's clinician. Cessation of NIV will be defined as occurring after six continuous hours without NIV.

\section{$\mathrm{ECCO}_{2} \mathrm{R}$}

Patients who are randomised to addition of $\mathrm{ECCO}_{2} \mathrm{R}$ will undergo cannulation in either the right internal jugular vein or one of the femoral veins using a 15.5 French double lumen $\mathrm{ECCO}_{2} \mathrm{R}$ cannula (patient and operator preference) using an ultrasound-guided Seldinger technique. The $\mathrm{ECCO}_{2} \mathrm{R}$ device, will be primed with $0.9 \%$ saline and 1 unit/mL heparin in accordance with the manufacturer's instructions. The blood flow will be titrated to the maximum achievable (usually $400-500 \mathrm{~mL} /$ minute) and sweep gas titrated up to $10 \mathrm{~L} /$ minute in $1 \mathrm{~L} /$ minute increments every $15 \mathrm{~min}$. $\mathrm{ECCO}_{2} \mathrm{R}$ will be 
titrated to achieve an arterial $\mathrm{pH}>7.35$, respiratory rate $<25$ and patient comfort with breathing. Discontinuation of NIV and $\mathrm{ECCO}_{2} \mathrm{R}$ will occur when judged appropriate by the patient's clinician. Cessation of $\mathrm{ECCO}_{2} \mathrm{R}$ will be defined as occurring after six continuous hours without $\mathrm{ECCO}_{2} \mathrm{R}$. All patients receiving ECCO2R will receive a continuous infusion of heparin to maintain an APTTr of 1.5-2 titrated using the hospital protocol. Data relating to the ICU inpatient stay will be collected from the ICU and hospital information systems. At 3 months following randomisation, a telephone interview will be conducted by the randomising study centre to ascertain the post-discharge survey data.

Whilst the patient remains on respiratory support (either NIV or $\mathrm{ECCO}_{2} \mathrm{R}$ ), all patients will undergo daily assessment of dyspnoea and comfort, spirometry, electrical impedance tomography, parasternal electromyography and oesophageal pressure monitoring.

\section{Electrical impedance tomography}

Electrical impedance tomography (EIT) is a non-invasive, bedside monitoring technique that provides semicontinuous, real-time information about the regional distribution of the changes in electrical resistivity of the lung tissue due to variations in ventilation (or blood perfusion) in relation to a reference state [48-50]. To generate an image, EIT repeatedly injects small alternating electric currents (usually $5 \mathrm{~mA}$ ) at high frequency of $50-$ $80 \mathrm{kHz}$ through a system of 16 skin electrodes applied circumferentially around the thorax in a single plane between the fourth and sixth intercostal space [51, 52]. While an adjacent pair of electrodes 'injects' the current, the remaining passive electrode pairs measure the differences in electric potential. A resistivity (impedance) image is reconstructed from these data by a mathematical algorithm [48-50]. Lungs have a changing impedance during the respiratory cycle due to changes in the air-tissue ratio. This variation in tidal impedance provides quantitative data on both changes in lung volume and regional distribution of air within the lung, allowing the recording of physiological phenomena with high temporal and functional resolution [53-56].

COPD is known to have significant spatial and temporal heterogeneity of ventilation due to the inhomogenous destruction of lung elastic tissue leading to loss of elastic recoil, regional ventilation inequality, increased airway resistance and dynamic hyperinflation. One of the key problems in exacerbations of COPD is the prolongation of the expiratory phase in COPD, resulting in the development of dynamic hyperinflation which leads to haemodynamic compromise, increased work of breathing and ventilator asynchrony $[57,58]$. Information derived from EIT indices, including the global inhomogeneity index, can be used to demonstrate both inhomogeneous ventilation and the development of dynamic hyperinflation [59-64]. One potential method to demonstrate dynamic hyperinflation is the mapping of expiratory time constants using the change in impedance over time [65, 66]. It is anticipated that time constants will correlate with other measures of global inhomogeneity and this will be used to describe the physiological consequences of NIV and $\mathrm{ECCO}_{2} \mathrm{R}$.

EIT will be undertaken unless there is a contraindication (pacemaker or implantable defibrillator). EIT examinations will be performed using the Drager Pulmovista 500 EIT device (Pulmovista ${ }^{\circ}$; Draeger, Luebek, Germany) using a silicone band consisting of 16 integrated electrodes and one reference electrode applied around the thorax at the fourth intercostal space in accordance with the manufacturer's instructions. Real-time analogue waveform outputs from the ventilators feed to an inbuilt data acquisition system (Draeger EIT Data Analysis Tool 6.1). Data will be analysed after processing using custom-made software and in accordance with the method described by the Translational EIT Development (TREND) study group [51]. Data will be displayed to demonstrate changes in tidal volume, end-expiratory lung volume, spatial distribution of gas and respiratory time constants [67-70]. Descriptors of the spatial distribution of ventilation, including the global inhomogeneity index [71-74] and the coefficient of variation [61,72, 75], will be reported. Additionally, the heterogeneity of ventilation will be quantified measuring regional respiratory time constants $[69,70]$, phase shifts in regional ventilation [76], the ventilation delay index [77] and heterogeneity of expiratory times $[61,62,78]$.

\section{Parasternal electromyography}

Exacerbations of COPD result in an increase in the subjective work of breathing, anxiety and tachypnoea, which in turn result in a progressive increase in the elevated neural respiratory drive mediated through the respiratory centre in the brainstem [79-81]. Although the output of the respiratory centre cannot be measured directly, a well validated surrogate measure is the electromyography (EMG) signal measured at the level of the parasternal intercostal muscles using surface electrodes placed over the second intercostal space [80, 82-84]. Parasternal EMG has been demonstrated to be a reproducible and well tolerated technique to assess neural respiratory drive [85], particularly for patients with an exacerbation of COPD [80, 81]. To allow physiologically meaningful comparisons of the EMG signal, the root mean square is used to quantify the intensity and duration of the contraction and has been shown to be linearly associated with 
increasing load on the muscle [86, 87]. Additional measures to quantify the neural respiratory drive are the percentage of the EMG signal of the maximum EMG signal obtained $\left(E M G_{\text {parammax }}\right)$ and the neural respiratory drive index (NRDI), which is the product of $\mathrm{EMG}_{\mathrm{para} \% \max }$ and the respiratory rate [80]. NRDI is a validated measure of work of breathing during an acute exacerbation and allows changes in work of breathing over time to be documented [80, 81].

EMG will be recorded from the parasternal second intercostal space bilaterally and then processed and analysed in accordance with previously published work [80, 81]. The root mean square will be used to calculate the root mean square $\mathrm{EMG}_{\text {param max }}$ from the maximum EMG signal obtained and the NRDI will be calculated by multiplying $\mathrm{EMG}_{\mathrm{para} \% \max }$ by the respiratory rate. Changes in an individual patient will then be analysed over time.

\section{Oesophageal pressure monitoring}

Oesophageal pressure $\left(\mathrm{P}_{\mathrm{ES}}\right)$ may be measured using an inflated balloon placed in the lower oesophagus and attached to an air-filled pressure transducer. The changes in $\mathrm{P}_{\mathrm{ES}}$ with respiration are concordant with the changes in pleural pressure $\left(\mathrm{P}_{\mathrm{PL}}\right)$ [88-90]. The difference between $\mathrm{P}_{\mathrm{ES}}$ and airway pressure $\left(\mathrm{P}_{\mathrm{AW}}\right)$ is a reasonable estimate of transpulmonary pressure $\left(\mathrm{P}_{\mathrm{L}}\right)$ in the region surrounding the balloon [89-91]. From this, the work of breathing can be calculated using the integration of the difference between the static compliance of the chest wall and the oesophageal pressure multiplied by volume over time. As chest wall compliance cannot be directly measured in spontaneously breathing patients, it will be estimated as normal, at $200 \mathrm{~mL} / \mathrm{cmH}_{2} \mathrm{O}$ [88, 91]. Respiratory muscle work will also be estimated using the pressure time product of the oesophageal pressure $\left(\mathrm{PTP}_{\mathrm{ES}}\right)[88,91] . \mathrm{PTP}_{\mathrm{ES}}$ is the integral of pressure over time and is the product of the change in pressure multiplied by the duration of the contraction $[88,91]$. The particular advantage of $\mathrm{PTP}_{\mathrm{ES}}$ is that it provides an estimate of activity regardless of whether or not a volume is generated. Due to the development of dynamic hyperinflation in exacerbations of COPD, the muscles of respiration commence contracting prior to airflow commencing [89, 92]. PTP $_{E S}$ estimates of the work undertaken during this isometric phase of contraction. Application of extrinsic PEEP can be titrated to minimise work of breathing [91].

Oesophageal pressure measurements will be undertaken using a 5 French latex free balloon catheter (Cooper Surgical, Conneticut, USA) inserted into the lower oesophagus trans-nasally with $0.5-1.5 \mathrm{~mL}$ of air instilled to allow optimal transmission of the pressure waveform [91]. The catheter is attached to a pressure transducer to obtain pressure measurements and simultaneous pneumotachograph recordings are made (Hans Rudolph differential pneumotachograph). The balloon position will be validated using the dynamic occlusion test in the spontaneously breathing patient $[92,93]$.$) . All$ signals will be collected on a personal computer through a 12-bit analogue-to-digital converter (National Instrument DAQCard 700; Austin, TX) at a sampling frequency of $200 \mathrm{~Hz}$ (ICU-lab, KleisTEK Engineering, Bari, Italy). Signals will be analysed using ICU-Lab software. The oesophageal pressure trace will be used to calculate work of breathing and the pressure time product will be calculated. Oesophageal pressure will be used solely as an outcome measure and will not be available for use at the bedside.

\section{Safety reporting}

The safety reporting window for this trial is from enrolment until completion of the interventional component of the trial (cessation of the device). Safety reporting will follow the standard operating procedure for Guy's and St Thomas' NHS Foundation Trust. Anticipated adverse events will be recorded as part of the trial information safety endpoints. All serious adverse events will be reported to the sponsors and manufacturer within one working day.

\section{Sample size}

It is estimated that the effect of addition of $\mathrm{ECCO}_{2} \mathrm{R}$ will be a reduction in NIV duration from $48 \mathrm{~h}$ to $36 \mathrm{~h}$. Group sample sizes of 24 (12 in each arm) patients achieve $80 \%$ power to reject the null hypothesis of equal means when the population mean difference is $12 \mathrm{~h}$ with a common standard deviation of $10 \mathrm{~h}$ with alpha level of $5 \%$.

\section{Sites and site monitoring}

The study will be conducted at up to five sites within the UK and monitored according to the standard operating procedure for site monitoring of the GSTT Trials Unit, which includes at least one site visit over the course of the trial as well as triggered visits if required. All data from the sites will be shared solely with the co-ordinating centre. Local sites will liaise directly with the manufacturers for equipment/disposables. The lead site will supervise all other aspects of the study and is available $24 \mathrm{~h}, 7$ days for questions relating to the study. The randomisation sequence is solely held at the lead centre who will also allocate trial participant numbers. All sites are University-affiliated hospitals with tertiary intensive care units experienced in the provision of extracorporeal $\mathrm{CO}_{2}$ removal. Current sites include Guy's and St Thomas' 
NHS Foundation Trust, Manchester University NHS Foundation Trust, Chelsea and Westminster NHS Foundation Trust and Queen Elizabeth University Hospital, Glasgow. Additional data about sites can be obtained from the corresponding author. Source data verification conducted over the course of the trial will be at least $1 \%$ and will increase if significant discrepancies are found.

\section{Protocol amendments}

Protocol amendments will be approved by both the sponsor and the REC prior to being implemented. Any protocol amendments will be numbered and dated and shared with investigating centres to ensure version control.

\section{Data and data monitoring}

The study will be conducted in accordance with the current approved protocol, ICH GCP, relevant regulations and standard operating procedures. Audits of data are not planned.

Regular monitoring will be performed according to ICH GCP. Data will be evaluated for compliance with the protocol and accuracy in relation to source documents. Following written standard operating procedures, the monitors will verify that the clinical trial is conducted and data are generated, documented and reported in compliance with the protocol, GCP and the applicable regulatory requirements.

Data will be stored in the department of Critical Care, Guy's and St Thomas' NHS Foundation Trust.

\section{Access to data}

Direct access will be granted to authorised representatives from the sponsor, host institution and regulatory authorities to permit trial-related monitoring, audits and inspections. The funder has access only to anonymised information embedded within the device which is not accessible to researchers. All other data remain the property of the researchers.

\section{Statistical analysis}

Summary measures for the baseline characteristics of each group will be presented as mean and standard deviation for continuous (approximate) normally distributed variables, medians and interquartile ranges for non-normally distributed variables, and frequencies and percentages for categorical variables. The planned primary efficacy analyses, difference between the two arms in reduction in NIV duration, will be analysed on randomized patients using a non-parametric approach, Mann-Whitney U test. Similar analyses as for the primary outcome measure will be conducted for secondary efficacy data. Missing data in the efficacy population will not be interpolated. All randomised participants in both arms with valid non-invasive ventilation data will be included in the analysis. Analysis of the physiological data will be per protocol, whilst analysis of outcomes will be intention to treat. Physiological data will be compared within individuals to describe a relative change in work of breathing. The statistical analysis plan can be accessed through the corresponding author. No subgroups have been planned.

\section{Discussion}

The use of $\mathrm{ECCO}_{2} \mathrm{R}$ for AECOPD [94] has progressively increased despite the lack of supporting evidence. This trial is in response to the recent call by NICE to increase the depth of evidence for $\mathrm{ECCO}_{2} \mathrm{R}$ [95]. In keeping with this, the key aims of the trial are to provide outcome, safety and physiological data about the use of ECCO2R in exacerbations of COPD. Given the relatively small size of the study, it is not expected that this work will provide a definitive answer as to the impact of $\mathrm{ECCO}_{2} \mathrm{R}$ on the mortality and intubation/mechanical ventilation in exacerbations of COPD. However, the detailed physiology which will be measured should allow an improved understanding of how $\mathrm{ECCO}_{2} \mathrm{R}$ impacts respiratory physiology. Exacerbations of COPD are one of the leading causes of hospital admission in the UK and the intensive care and hospital costs for patients who do not respond to first-line non-invasive ventilation are significant for the NHS. Consequently, it is important to also measure the economic cost of this approach for patients with significant exacerbations of COPD. The clinical relevance of this work is potentially highly significant-both the mechanisms and outcomes of ECCO2R in AECOPD are the subject of research efforts and clinical interest.

\section{Publication policy}

The trial will be submitted to relevant professional congresses in abstract format as well as submitted to the peer-reviewed literature. Participants will be notified of the trial results in writing, if they consent to be contacted. There are no restrictions on publication.

\section{Data monitoring committee}

Given the number of participants and predominantly physiological endpoints, a data monitoring committee was not required.

\section{Trial status}

At the time of manuscript submission, the trial is still currently recruiting participants.

\section{Sponsorship}

The trial is sponsored by Guy's and St Thomas' NHS Foundation Trust, Westminster Bridge Rd, London SE1 7EH, UK. The sponsor carries insurance to compensate 
any patients who suffer trial-related harm. The sponsor is independent of the design, conduct, analysis and reporting of the study.

\section{Additional files}

Additional file 1: Contains a consultee assent form, Consultee information sheet, the participant consent and the participant information sheet. (ZIP $339 \mathrm{~kb}$ )

Additional file 2: SPIRIT 2013 Checklist: Recommended items to address in a clinical trial protocol and related documents*. (DOC 124 kb)

\section{Abbreviations}

AECOPD: Acute exacerbation of chronic obstructive respiratory disease; APACHE II: Acute Physiology And Chronic Health Evaluation II; APTTr: Activated partial thromboplastin time ratio; $\mathrm{CO}_{2}$ : Carbon dioxide; COPD: Chronic obstructive pulmonary disease; $\mathrm{ECCO}_{2} \mathrm{R}$ : Extracorporeal carbon dioxide removal; EIT: Electrical impedance tomography; EMG: Electromyography; $E_{M G}$ aramax: Percentage of the electromyography signal of the maximum electromyography signal obtained; $\mathrm{FiO}_{2}$ : Fraction of inspired oxygen; GOLD: Global Initiative for Chronic Obstructive Lung Disease; ICH GCP: International Committee for Harmonisation of Good Clinical Practice; ICU: Intensive care unit; INR: International normalised ratio; NIV: Non-invasive; NOK: Next of kin; NRDI: Neural respiratory drive index; NYHA: New York Heart Association; $\mathrm{PaCO}_{2}$ : Arterial partial pressure of carbon dioxide; $\mathrm{PaO}_{2} / \mathrm{FiO}_{2}$ : Arterial partial pressure of oxygen to fraction of inspired oxygen ratio; $P_{\text {AW: }}$ : Airway pressure; PEEP: Positive end expiratory pressure; $P_{E S}$ : Oesophageal; $P_{L}$ : Transpulmonary pressure; $P_{P L}$ : Pleural pressure; PTPES: Pressure time product of the oesophageal pressure; QALY: Quality adjusted life year; REC: Research ethics committee; T: Time

\section{Acknowledgements}

The authors acknowledge the support of the critical care team at Guy's and St Thomas' NHS Foundation Trust, without whose support this trial would not have been possible.

\section{Authors' contributions}

$\mathrm{NB}, \mathrm{LC}$ and $\mathrm{NH}$ designed the original protocol with $\mathrm{AD}$ providing original statistical advice. All authors contributed to the manuscript. All authors will have a material contribution to the study at one or more stages with no involvement by professional writers. The views expressed are those of the authors and not necessarily those of the NHS or Alung Technologies Inc. All authors read and approved the final manuscript.

\section{Funding}

The study is funded by Alung Technologies Inc. The funder is independent of the design, conduct, analysis and reporting of the study.

\section{Availability of data and materials}

Data sharing is not applicable to this article as no datasets were generated or analysed during the current study.

\section{Ethics approval and consent to participate}

The trial protocol (version 1.5 dated 15 March 2018) has been approved by the Cambridge NHS Human Research Authority Research Ethics Committee (14/EE/0109). All variations in the protocol are submitted to both the sponsor and REC for approval prior to implementation. All participants, or their designated representative, will be asked for consent prior to trial entry. Consent documentation (information sheets and consent forms in Additional file 1).

\section{Consent for publication}

Not applicable.

\section{Competing interests}

The authors declare that they have no competing interests.

\section{Author details}

'Department of Critical Care, Guy's and St Thomas' NHS Foundation Trust, Westminster Bridge Rd, London SE1 7EH, UK. ${ }^{2}$ Centre for Human \& Applied Physiological Sciences (CHAPS), School of Basic \& Medical Biosciences, Faculty of Life Sciences \& Medicine, King's College London, London, UK. 'Lane Fox Respiratory Unit, Guy's and St Thomas' NHS Foundation Trust, Westminster Bridge Rd, London SE1 7EH, UK. ${ }^{4}$ School of Population Health \& Environmental Sciences, King's College London, London WC2R 2LS, UK.

${ }^{5}$ National Institute for Health Research Biomedical Research Centre, Guy's and St Thomas' NHS Trust and King's College London, London, UK.

Received: 19 November 2018 Accepted: 29 June 2019

Published online: 30 July 2019

\section{References}

1. Vestbo J, Hurd SS, Agusti AG, Jones PW, Vogelmeier C, Anzueto A, et al. Global strategy for the diagnosis, management, and prevention of chronic obstructive pulmonary disease: GOLD executive summary. Am J Respir Crit Care Med. 2013;187(4):347-65.

2. Spencer S, Calverley PM, Burge PS, Jones PW. Impact of preventing exacerbations on deterioration of health status in COPD. Eur Respir J. 2004;23(5):698-702.

3. Kessler R, Stahl E, Vogelmeier C, Haughney J, Trudeau E, Lofdahl CG, et al. Patient understanding, detection, and experience of COPD exacerbations: an observational, interview-based study. Chest. 2006;130(1):133-42.

4. Garcia-Aymerich J, Farrero E, Felez MA, Izquierdo J, Marrades RM, Anto JM. Risk factors of readmission to hospital for a COPD exacerbation: a prospective study. Thorax. 2003;58(2):100-5.

5. Anzueto A. Impact of exacerbations on COPD. Eur Respir Rev. 2009;19(116):113-8.

6. Pauwels RA, Buist AS, Calverley PM, Jenkins CR, Hurd SS. Global strategy for the diagnosis, management, and prevention of chronic obstructive pulmonary disease. NHLBI/WHO Global Initiative for Chronic Obstructive Lung Disease (GOLD) Workshop summary. Am J Respir Crit Care Med. 2001;163(5):1256-76.

7. Donaldson GC, Seemungal TA, Bhowmik A, Wedzicha JA. Relationship between exacerbation frequency and lung function decline in chronic obstructive pulmonary disease. Thorax. 2002;57(10):847-52.

8. Seemungal T, Sykes A. Recent advances in exacerbations of COPD. Thorax. 2008;63(10):850-2.

9. Seemungal TA, Donaldson GC, Bhowmik A, Jeffries DJ, Wedzicha JA. Time course and recovery of exacerbations in patients with chronic obstructive pulmonary disease. Am J Respir Crit Care Med. 2000;161(5):1608-13.

10. Kanner RE, Anthonisen NR, Connett JE. Lower respiratory illnesses promote FEV (1) decline in current smokers but not ex-smokers with mild chronic obstructive pulmonary disease: results from the lung health study. Am J Respir Crit Care Med. 2001;164(3):358-64.

11. Kesten S, Celli B, Decramer M, Liu D, Tashkin D. Adverse health consequences in COPD patients with rapid decline in FEV1 - evidence from the UPLIFT trial. Respir Res. 2011;12:129.

12. Anzueto A, Leimer I, Kesten S. Impact of frequency of COPD exacerbations on pulmonary function, health status and clinical outcomes. Int J Chron Obstruct Pulmon Dis. 2009;4:245-51.

13. Ankjaergaard KL, Rasmussen $D B$, Schwaner SH, Andreassen HF, Hansen EF, Wilcke JT. COPD: Mortality and readmissions in relation to number of admissions with noninvasive ventilation. Copd. 2017;14(1):30-6.

14. Burge S, Wedzicha JA. COPD exacerbations: definitions and classifications. Eur Respir J Suppl. 2003;41:46s-53s.

15. Ram FS, Picot J, Lightowler J, Wedzicha JA. Non-invasive positive pressure ventilation for treatment of respiratory failure due to exacerbations of chronic obstructive pulmonary disease. Cochrane Database Syst Rev. 2004;(3):Cd004104. https://www.ncbi.nIm.nih.gov/ pubmed/14974057.

16. Osadnik CR, Tee VS, Carson-Chahhoud KV, Picot J, Wedzicha JA, Smith BJ. Non-invasive ventilation for the management of acute hypercapnic respiratory failure due to exacerbation of chronic obstructive pulmonary disease. Cochrane Database Syst Rev. 2017;7:Cd004104.

17. Rochwerg B, Brochard L, Elliott MW, Hess D, Hill NS, Nava S, et al. Official ERS/ATS clinical practice guidelines: noninvasive ventilation for acute respiratory failure. Eur Respir J. 2017;50(2). https://www.ncbi.nlm.nih.gov/ pubmed/28860265. 
18. Brochard L, Mancebo J, Wysocki M, Lofaso F, Conti G, Rauss A, et al. Noninvasive ventilation for acute exacerbations of chronic obstructive pulmonary disease. N Engl J Med. 1995;333(13):817-22.

19. Lightowler JV, Wedzicha JA, Elliott MW, Ram FS. Non-invasive positive pressure ventilation to treat respiratory failure resulting from exacerbations of chronic obstructive pulmonary disease: Cochrane systematic review and meta-analysis. BMJ. 2003;326(7382):185.

20. Appendini L, Patessio A, Zanaboni S, Carone M, Gukov B, Donner C. Physiologic effects of positive endexpiratory pressure and mask pressure support during exacerbations of chronic obstructive pulmonary disease. Am J Respir Crit Care Med. 1994;149(5):1069-76.

21. Demoule A, Girou E, Richard JC, Taille S, Brochard L. Increased use of noninvasive ventilation in French intensive care units. Intensive Care Med. 2006;32(11):1747-55

22. Abroug F, Ouanes-Besbes L, Hammouda Z, Benabidallah S, Dachraoui F, Ouanes I, et al. Noninvasive ventilation with helium-oxygen mixture in hypercapnic COPD exacerbation: aggregate meta-analysis of randomized controlled trials. Ann Intensive Care. 2017;7(1):59.

23. Ozsancak Ugurlu A, Habesoglu MA. Epidemiology of NIV for acute respiratory failure in COPD patients: Results from the international surveys vs. the "real world". Copd. 2017;14(4):429-38.

24. Contou D, Fragnoli C, Cordoba-Izquierdo A, Boissier F, Brun-Buisson C, Thille AW. Noninvasive ventilation for acute hypercapnic respiratory failure: intubation rate in an experienced unit. Respir Care. 2013;58(12):2045-52.

25. Carratu P, Bonfitto P, Dragonieri S, Schettini F, Clemente R, Di Gioia G, et al. Early and late failure of noninvasive ventilation in chronic obstructive pulmonary disease with acute exacerbation. Eur J Clin Investig. 2005;35(6):404-9.

26. Kumar S, Khilnani GC, Banga A, Sharma SK. Predictors of requirement of mechanical ventilation in patients with chronic obstructive pulmonary disease with acute respiratory failure. Lung India. 2013;30(3):178-82.

27. Confalonieri M, Garuti G, Cattaruzza MS, Osborn JF, Antonelli M, Conti G, et al. A chart of failure risk for noninvasive ventilation in patients with COPD exacerbation. Eur Respir J. 2005;25(2):348-55.

28. Chandra D, Stamm JA, Taylor B, Ramos RM, Satterwhite L, Krishnan JA, et al. Outcomes of noninvasive ventilation for acute exacerbations of chronic obstructive pulmonary disease in the United States, 1998-2008. Am J Respir Crit Care Med. 2012;185(2):152-9.

29. Martin-Gonzalez F, Gonzalez-Robledo J, Sanchez-Hernandez F, MorenoGarcia MN, Barreda-Mellado I. Effectiveness and predictors of failure of noninvasive mechanical ventilation in acute respiratory failure. Med Intensiva. 2016;40(1):9-17.

30. Barrett NA, Camporota L. The evolving role and practical application of extracorporeal carbon dioxide removal in critical care. Crit Care Resusc. 2017;19(Suppl 1):62-7.

31. Camporota L, Barrett N. Current applications for the use of extracorporeal carbon dioxide removal in critically ill patients. Biomed Res Int. 2016:2016:9781695.

32. Batchinsky Al, Jordan BS, Regn D, Necsoiu C, Federspiel WJ, Morris MJ, et al. Respiratory dialysis: reduction in dependence on mechanical ventilation by venovenous extracorporeal CO2 removal. Crit Care Med. 2011;39(6):1382-7.

33. Wearden PD, Federspiel WJ, Morley SW, Rosenberg M, Bieniek PD, Lund LW, et al. Respiratory dialysis with an active-mixing extracorporeal carbon dioxide removal system in a chronic sheep study. Intensive Care Med. 2012; 38(10):1705-11.

34. Ruberto F, Pugliese F, D'Alio A, Perrella S, D'Auria B, lanni S, et al. Extracorporeal removal $\mathrm{CO} 2$ using a venovenous, low-flow system (Decapsmart) in a lung transplanted patient: a case report. Transplant Proc. 2009;41(4):1412-4

35. Cardenas VJ Jr, Lynch JE, Ates R, Miller L, Zwischenberger JB. Venovenous carbon dioxide removal in chronic obstructive pulmonary disease: experience in one patient. ASAIO J. 2009:55(4):420-2.

36. Dorrington KL, McRae KM, Gardaz JP, Dunnill MS, Sykes MK, Wilkinson AR. A randomized comparison of total extracorporeal $\mathrm{CO} 2$ removal with conventional mechanical ventilation in experimental hyaline membrane disease. Intensive Care Med. 1989;15(3):184-91.

37. Livigni S, Maio M, Ferretti E, Longobardo A, Potenza R, Rivalta L, et al. Efficacy and safety of a low-flow veno-venous carbon dioxide removal device: results of an experimental study in adult sheep. Crit Care. 2006;10(5):R151.

38. Schmidt W, Herth F, Mani R, Burki N. Extracorporeal CO2 removal with the hemolung respiratory assist system: Preliminary results of a pilot study. DIVI2011. https://www.ncbi.n/m.nih.gov/pubmed/23460154
39. Moss CE, Galtrey EJ, Camporota L, Meadows C, Gillon S, loannou N, et al. A retrospective observational case series of low-flow venovenous extracorporeal carbon dioxide removal use in patients with respiratory failure. ASAIO J. 2016:62(4):458-62.

40. Garcia JP, Kon ZN, Evans C, Wu Z, lacono AT, McCormick B, et al. Ambulatory veno-venous extracorporeal membrane oxygenation: innovation and pitfalls. J Thorac Cardiovasc Surg. 2011;142(4):755-61.

41. Kluge S, Braune SA, Engel M, Nierhaus A, Frings $D$, Ebelt $H$, et al. Avoiding invasive mechanical ventilation by extracorporeal carbon dioxide removal in patients failing noninvasive ventilation. Intensive Care Med. 2012;38(10):1632-9.

42. Burki NK, Mani RK, Herth FJ, Schmidt W, Teschler H, Bonin F, et al. A novel extracorporeal $\mathrm{CO}_{2}$ removal system: results of a pilot study of hypercapnic respiratory failure in patients with COPD. Chest. 2013;143(3):678-86.

43. Braune $S$, Sieweke A, Brettner F, Staudinger T, Joannidis M, Verbrugge S, et al. The feasibility and safety of extracorporeal carbon dioxide removal to avoid intubation in patients with COPD unresponsive to noninvasive ventilation for acute hypercapnic respiratory failure (ECLAIR study): multicentre case-control study. Intensive Care Med. 2016;42(9):1437-44.

44. Abrams D, Brodie D. Emerging indications for extracorporeal membrane oxygenation in adults with respiratory failure. Ann Am Thorac Soc. 2013;10(4):371-7.

45. Sklar MC, Beloncle F, Katsios CM, Brochard L, Friedrich JO. Extracorporeal carbon dioxide removal in patients with chronic obstructive pulmonary disease: a systematic review. Intensive Care Med. 2015;41(10):1752-62.

46. Pisani L, Fasano L, Corcione N, Comellini V, Guerrieri A, Ranieri MV, et al. Effects of extracorporeal $\mathrm{CO} 2$ removal on inspiratory effort and respiratory pattern in patients who fail weaning from mechanical ventilation. Am J Respir Crit Care Med. 2015;192(11):1392-4.

47. NICE. Chronic obstructive pulmonary disease in over 16s: diagnosis and management: NICE; 2018. https://www.nice.org.uk/guidance/ng115.

48. Bayford R. Bioimpedance tomography (electrical impedance tomography). Annu Rev Biomed Eng. 2006;8:63-91.

49. Brown BH. Electrical impedance tomography (EIT): a review. J Med Eng Technol. 2003;27(3):97-108.

50. Bodenstein M, David M, Markstaller K. Principles of electrical impedance tomography and its clinical application. Crit Care Med. 2009;37(2):713-24.

51. Frerichs I, Amato MB, van Kaam AH, Tingay DG, Zhao Z, Grychtol B, et al. Chest electrical impedance tomography examination, data analysis, terminology, clinical use and recommendations: consensus statement of the TRanslational EIT developmeNt stuDy group. Thorax. 2016. https:// www.ncbi.nlm.nih.gov/pubmed/27596161.

52. Frerichs $I z$, Becher $T$, Weiler N. Methodology of electrical impedance tomography-derived measures of regional lung ventilation. 2014:1. https:// ccforum.biomedcentral.com/articles/10.1186/s13054-014-0635-5.

53. Costa EL, Lima RG, Amato MB. Electrical impedance tomography. Curr Opin Crit Care. 2009;15(1):18-24

54. Moerer O, Hahn G, Quintel M. Lung impedance measurements to monitor alveolar ventilation. Curr Opin Crit Care. 2011;17(3):260-7.

55. Muders $\mathrm{T}$, Luepschen $\mathrm{H}$, Putensen $\mathrm{C}$. Impedance tomography as a new monitoring technique. Curr Opin Crit Care. 2010;16(3):269-75.

56. Bikker IG, Preis C, Egal M, Bakker J, Gommers D. Electrical impedance tomography measured at two thoracic levels can visualize the ventilation distribution changes at the bedside during a decremental positive end-expiratory lung pressure trial. Crit Care. 2011;15(4):R193.

57. Laghi F, Goyal A. Auto-PEEP in respiratory failure. Minerva Anestesiol. 2012;78(2):201-21.

58. Brandolese R, Broseghini C, Polese G, Bernasconi M, Brandi G, Milic-Emili J, et al. Effects of intrinsic PEEP on pulmonary gas exchange in mechanically-ventilated patients. Eur Respir J. 1993;6(3):358-63.

59. Balleza M, Calaf N, Feixas T, Gonzalez M, Anton D, Riu PJ, et al. Measuring breathing pattern in patients with chronic obstructive pulmonary disease by electrical impedance tomography. Archivos de bronconeumologia. 2009:45(7):320-4.

60. Trenk F, Mendes L, Carvalho P, Paiva RP, Henriques J, Maglaveras N, et al. Evaluation of lung ventilation distribution in chronic obstructive pulmonary disease patients using the global inhomogeneity index. Conf Proc IEEE Eng Med Biol Soc. 2016;2016:5286-9.

61. Vogt B, Pulletz S, Elke G, Zhao Z, Zabel P, Weiler N, et al. Spatial and temporal heterogeneity of regional lung ventilation determined by electrical impedance tomography during pulmonary function testing. J. Appl Physiology (1985). 2012;113(7):1154-61. 
62. Vogt B, Zhao Z, Zabel P, Weiler N, Frerichs I. Regional lung response to bronchodilator reversibility testing determined by electrical impedance tomography in chronic obstructive pulmonary disease. Am J Physiol Lung Cell Mol Physiol. 2016;311(1):L8-I19.

63. Mauri T, Bellani G, Salerno D, Mantegazza F, Pesenti A. Regional distribution of air trapping in chronic obstructive pulmonary disease. Am J Respir Crit Care Med. 2013;188(12):1466-7

64. Kostakou E, Barrett N, Camporota L. Electrical impedance tomography to determine optimal positive end-expiratory pressure in severe chronic obstructive pulmonary disease. Crit Care. 2016:1-2.

65. Crabb M, Grychtol B, Lionheart W, Camporota L, editors. EIT regional time constants. 2016.

66. R'oka P, Waldmann A, Ender F, Bohm S, Windisch W, Strassmann S, et al. Expiratory time constants by electrical impedance tomography in hypoxemic and hypercapnic acute lung failure - a feasibility study. Int Care Med Exp. 2015;3(Supp 1):495

67. Mauri T, Bellani G, Confalonieri A, Tagliabue P, Turella M, Coppadoro A, et al. Topographic distribution of tidal ventilation in acute respiratory distress syndrome: effects of positive end-expiratory pressure and pressure support. Crit Care Med. 2013;41(7):1664-73.

68. Frerichs I, Dargaville PA, Dudykevych T, Rimensberger PC. Electrical impedance tomography: a method for monitoring regional lung aeration and tidal volume distribution? Intensive Care Med. 2003;29(12):2312-6.

69. Pulletz S, Kott M, Elke G, dler DS, Vogt B, Weiler N, et al. Dynamics of regional lung aeration determined by electrical impedance tomography in patients with acute respiratory distress syndrome. 2012;7(1):1. https://www. ncbi.nlm.nih.gov/pmc/articles/PMC3528404/.

70. Miedema M, de Jongh FH, Frerichs I, van Veenendaal MB, van Kaam AH. Regional respiratory time constants during lung recruitment in high-frequency oscillatory ventilated preterm infants. Intensive Care Med. 2012;38(2):294-9.

71. Becher T, Kott M, Schadler D, Vogt B, Meinel T, Weiler N, et al. Influence of tidal volume on ventilation inhomogeneity assessed by electrical impedance tomography during controlled mechanical ventilation. Physiol Meas. 2015;36(6):1137-46.

72. Becher T, Vogt B, Kott M, Schadler D, Weiler N, Frerichs I. Functional regions of interest in electrical impedance tomography: A secondary analysis of two clinical studies. PLoS One. 2016;11(3):e0152267.

73. Zhao Z, Moller K, Steinmann D, Frerichs I, Guttmann J. Evaluation of an electrical impedance tomography-based Global Inhomogeneity Index for pulmonary ventilation distribution. Intensive Care Med. 2009;35(11):1900-6.

74. Zhao Z, Pulletz S, Frerichs I, Muller-Lisse U, Moller K. The ElT-based global inhomogeneity index is highly correlated with regional lung opening in patients with acute respiratory distress syndrome. BMC Res Notes. 2014;7:82.

75. Frerichs I, Achtzehn U, Pechmann A, Pulletz S, Schmidt EW, Quintel M, et al. High-frequency oscillatory ventilation in patients with acute exacerbation of chronic obstructive pulmonary disease. J Crit Care. 2012;27(2):172-81.

76. Riedel T, Kyburz M, Latzin P, Thamrin C, Frey U. Regional and overall ventilation inhomogeneities in preterm and term-born infants. Intensive Care Med. 2009;35(1):144-51.

77. Wrigge H, Zinserling J, Muders T, Varelmann D, Gunther U, von der Groeben C, et al. Electrical impedance tomography compared with thoracic computed tomography during a slow inflation maneuver in experimental models of lung injury. Crit Care Med. 2008:36(3):903-9.

78. Frerichs I, Zhao Z, Becher T, Zabel P, Weiler N, Vogt B. Regional lung function determined by electrical impedance tomography during bronchodilator reversibility testing in patients with asthma. Physiol Meas. 2016;37(6):698-712.

79. Jolley CJ, Luo YM, Steier J, Rafferty GF, Polkey MI, Moxham J. Neural respiratory drive and breathlessness in COPD. Eur Respir J. 2015:45(2):355-64.

80. Murphy PB, Kumar A, Reilly C, Jolley C, Walterspacher S, Fedele F, et al. Neural respiratory drive as a physiological biomarker to monitor change during acute exacerbations of COPD. Thorax. 2011;66(7):602-8.

81. Suh ES, Mandal S, Harding R, Ramsay M, Kamalanathan M, Henderson K, et al. Neural respiratory drive predicts clinical deterioration and safe discharge in exacerbations of COPD. Thorax. 2015;70(12):1123-30.

82. Petit JM, Milic-Emili G, Delhez L. Role of the diaphragm in breathing in conscious normal man: an electromyographic study. J Appl Physiol. 1960;15:1101-6.

83. Sinderby C, Spahija J, Beck J. Diaphragm activation during exercise in chronic obstructive pulmonary disease. Am J Respir Crit Care Med. 2001;163:1637-41.
84. Jolley CJ, Moxham J. A physiological model of patient-reported breathlessness during daily activities in COPD. Eur Respir Rev. 2009;18(112):66-79.

85. Steier J, Jolley CJ, Polkey MI, Moxham J. Nocturnal asthma monitoring by chest wall electromyography. Thorax. 2011;66(7):609-14.

86. Fukuda T, Echeimberg J, Pompeu J, Lucareli P, Garbelotti S, Gimenes R, et al. Root mean square value of the electromyographic signal in the isometric torque of the quadriceps, hamstrings and brachial biceps muscles in female subjects. J Appl Res. 2010;10(1):32-9.

87. Fridlund AJ, Cacioppo JT. Guidelines for human electromyographic research. Psychophysiology. 1986;23(5):567-89.

88. Benditt JO. Esophageal and gastric pressure measurements. Respir Care. 2005;50(1):68-75 discussion -7.

89. Bellani G, Pesenti A. Assessing effort and work of breathing. Curr Opin Crit Care. 2014;20(3):352-8.

90. Hedenstierna G. Esophageal pressure: benefit and limitations. Minerva Anestesiol. 2012;78(8):959-66.

91. Akoumianaki E, Maggiore SM, Valenza F, Bellani G, Jubran A, Loring SH, et al. The application of esophageal pressure measurement in patients with respiratory failure. Am J Respir Crit Care Med. 2014;189(5):520-31.

92. Brochard L. Measurement of esophageal pressure at bedside: pros and cons. Curr Opin Crit Care. 2014;20(1):39-46.

93. Baydur A, Behrakis PK, Zin WA, Jaeger M, Milic-Emili J. A simple method for assessing the validity of the esophageal balloon technique. Am Rev Respir Dis. 1982;126(5):788-91.

94. Cummins C, Bentley AH, McAuley DF, McNamee JJ, Patrick H, Barrett NA. A United Kingdom Register study of in-hospital outcomes of patients receiving extracorporeal carbon dioxide removal. J Intensive Care Soc. 2018;19(2):114-21.

95. NICE. National Institute for Health and Care Excellence Interventional Procedure Guidance 428. London: Extracorporeal membrane carbon dioxide removal; 2012.

\section{Publisher's Note}

Springer Nature remains neutral with regard to jurisdictional claims in published maps and institutional affiliations.
Ready to submit your research? Choose BMC and benefit from:

- fast, convenient online submission

- thorough peer review by experienced researchers in your field

- rapid publication on acceptance

- support for research data, including large and complex data types

- gold Open Access which fosters wider collaboration and increased citations

- maximum visibility for your research: over $100 \mathrm{M}$ website views per year

At BMC, research is always in progress.

Learn more biomedcentral.com/submissions 